\title{
Colonoscopy: do operator motions and posture count?
}

Author

Institution
John Anderson

Department of Gastroenterology, Gloucestershire Hospitals NHS Foundation Trust, Cheltenham, United Kingdom submitted 28. October 2015 accepted after revision 3. November 2015

\section{Bibliography}

Dol http://dx.doi.org/ 10.1055/s-0041-109402 Endoscopy International Open 2015; 03: E627-E628 (c) Georg Thieme Verlag KG Stuttgart · New York E-ISSN 2196-9736

\section{Corresponding author}

John Anderson, MD

Department of Gastroenterology Gloucestershire Hospitals NHS Foundation Trust Sanford Road Cheltenham GL537AN United Kingdom jtanderson.endo@btinternet. com
Despite the routine use of colonoscopy as both a diagnostic and a therapeutic modality, the training necessary to perform safe and effective colonoscopy has not been standardized. Although colonoscopy requires complex psychomotor skills, at present the majority of countries determine the acquisition of competence based on the number of procedures an individual has performed, or on surrogates for competence (e.g., the cecal intubation rate or adenoma detection rate). The study by Ratuapli et al. uses kinematic analysis in an attempt to address some of the joint mechanics associated with skills acquisition by new endoscopy trainees. Very limited data have been published related to colonoscopy technique, as opposed to the other reasons for not succeeding to complete a procedure. Even fewer data address the mechanics of limb and joint movements and the associated pressure required.

Any technique may ultimately be successful in achieving intubation of the cecum. However, trainees exposed to or taught a variety of different techniques have no defined standard template toward which they can work $[1,2]$. The study by Ratuapli et al. hypothesizes that the range of joint movement may decrease as experience in colonoscopy is acquired [3]. This hypothesis has no hard foundation but is logical. As in the acquisition of many technical skills, trial and error often will result in an individual's determining which technique is the most effective for gaining a successful outcome. The effectiveness of any technique is tested as complexity or difficulty increases. Adaptation, modification, or refinement tends to occur over time. This can be through structured training or, as is commonly observed in endoscopic practice, experiential learning-effectively, trial and error. Interestingly, there is a very limited use of models and simulators to help with the process of acquiring endoscopy skills. This study used a simulator to add consistency to the task while attempting to measure other potential variables. Technical refinements for the study group were developed in direct clinical practice and during interaction with patients.

In colonoscopy, the more complex the challenge, the greater the likelihood that both the right and left hands will need to work independently toward a common goal. To ensure that tip control is optimally accurate, the right hand will control the shaft of the instrument while the left hand manages the control head of the instrument. This is an interesting deviation from the original design and expected use. The basic design has remained largely unchanged since the advent of the large-scale commercial production and routine use of endoscopes. Historically, the right hand was used to move the angulation controls, often leading to excessive, uncontrolled, rapid angulation of the tip. While this was occurring, the lack of control of the shaft could result in a loss of position or orientation.

Two-person colonoscopy can overcome some of these problems but leads to other issues of control related to insertion and withdrawal, plus the application of any torque necessary. In modern practice, there is a perceived optimal technique of a single operator using two hands independently to control the instrument. In colonoscopy, the right hand is employed to control rate and depth of insertion and withdrawal, and also to apply rotational force along the longitudinal axis of the instrument (torque). When torque is employed with tip angulation, it is possible to torque-steer the instrument. This is a highly effective and efficient method to steer the tip of the instrument around bends and angulations within the colon. To perform this technique efficiently, the instrument must be rolled. Ergonomically, this is best achieved with a "cigar-rolling" technique. Frequently, particularly in the early phase of training, a fist grip is used to achieve torque. The limited range of movements of the wrist will also limit the amount of torque that can be achieved 
without releasing the shaft of the instrument and repositioning the hand. In practice, it is not unreasonable to assume that unless the examiner is instructed otherwise, a fist grip may be employed, and excessive angulation of the joints in the wrist will be seen. As experience is gained, a more efficient method of torquesteering may be discovered and employed, resulting in less angulation of the wrist joint. The study does not report any instruction on how the right hand should be used to manipulate the shaft of the instrument, so no such conclusions can be drawn from the data.

Simulators may pose their own drawbacks. Using the patient's bed to support the weight of the shaft of the instrument facilitates more effective torque by the fingers. If the shaft is pulled by gravity, then additional effort is needed to prevent the scope from slipping out of the patient's anus while one is simultaneously trying to apply torque. The freestanding configuration of the simulator increases the likelihood of this occurring; or if in actual practice the scope falls off the bed, a similar effect is observed. The resultant pressure and force required may be too great for the fingers alone, resulting in the use of a fist grip and a reduction in the range of torque that can be applied - largely limited by the range of movements of the right wrist. This problem may have influenced the outcome of the kinematics study. The starting position of the right hand with a cigar-rolling technique would not be in a parasagittal plane; it would be with the wrist in a pronated position, with the thumb and little finger both pointing at the floor. Torque would not significantly affect this position other than for some flexion and extension as the fingers roll on the shaft.

Posture and the mechanics and forces used in colonoscopy practice are fundamental to technique. The publication of more studies addressing kinematics, ergonomics, and basic endoscopehandling techniques may help identify optimal techniques and encourage a more uniform approach to training. Furthermore, such studies might lead to the ability to identify and correct practices that can lead to repetitive strain injuries, with an adverse effect on the individual, the individual's performance, and the service delivered.

\section{Competing interests: None}

\section{References}

1 Lee TD, Swinnen SP, Serrien DJ. Cognitive effort and motor learning. Quest 1994; 46: 328 - 344

2 Sivak MV Jr. The art of endoscopic instruction. Gastrointest Endosc Clin North Am 1995; 5: 299-310

3 Ratuapli SK, Ruff KC, Ramirez FC et al. Kinematic analysis of wrist motion during simulated colonoscopy in first year gastroenterology fellows. Endosc Int Open 2015; 3: 621 -626 